\title{
THE CHALLENGE OF ORAL DRILLS
}

\author{
Ruth Hok \\ University of Michigan
}

In view of the growing interest in, and the current emphasis on the effectiveness of oral drills in language teaching, a few words concerning the teacher's approach to them may prove of value.

As Bowen says in the September 1959 PMLA, "There may be some teachers who find these drills dull."1 He was speaking of exercises he helped create in the recently published textbook for college students of beginning Spanish. ${ }^{2}$ But who will deny that drill of any kind for whatever purpose can be dull? Let us emphasize can be, for I propose to direct our attention in the next paragraphs to certain attitudes and procedures which should reassure language teachers new to this approach.

If we accept the theory that learning a language is learning a habit, if we agree with Bloomfield ${ }^{3}$ that "Language learning is overlearning: anything less is of no use," if we obey his dictum to "... get the forms by heart, and ... practice them over and over again, day after day, until they become entirely natural and familiar," then drill work seems inevitable. For it is through the predictable, repetitive nature of an exercise as spoken over and over that the language habit is formed, enabling the student finally to feel confident that he can proceed correctly on his own outside the drill setting. This is the nature and the goal of the oral drill. The teacher sets the pattern that the students are to imitate either by simply mimicking or by more complicated procedures of combining something new with something already learned. In language drill as in any drill the student always knows what is expected of him and should in every instance-provided the drill is properly adapted to his ability-be able to produce a correct utterance.

But it must be the teacher who works in a mechanical fashion only with his voice to whom Bowen refers when he says that "Teachers inevitably tire of drill material before students do ..." for I assume that "tire of" means "become bored with." Actually this type of teaching can utilize many facets of the teacher's being: brain, personality, intuition, ingenuity, physical stamina. It is for this reason that oral drills, if properly done, are exhausting before they are boring. 
Now the main pre-occupation of any teacher in any class is to see that the students are learning, that they are in a willing frame of mind, that the time is being used efficiently, and that the subject matter is presented to best advantage. Bored students are no more to be desired than are bored teachers; and the more successful the teacher is in conducting exercises -drill type included-the more adept he will be at finding challenges for his students, operating as he does on the principle that a learning student is not a bored one.

Since we conceive of language as being a means of conveying ideas, it might seem that the primary problem in language teaching is one of finding a subject on which all the members of the class have ideas to contribute in an oral discussion.

This may certainly be true in the later stages of learning a new language, but in the beginning it is the devices-the pronunciation and the grammar-by which the ideas are conveyed and not the ideas themselves that must be our concern. And it is these devices that must be formed into habits through their constant repetition. Obviously, the more nearly the student approaches the unawareness characteristic of native speakers visa-vis the language devices used, the more perfectly the teacher's task has been accomplished. The trick then is to center the student's attention where the teacher judges it should be, either on the device to be mastered or on the thought to be conveyed.

Many things not yet clearly understood determine what is usually thought of as language learning aptitude: age, previous training in other fields, other language learning experience, the physical condition of the ears and speech organs, what is loosely termed the student's "personality type," etc., to say nothing of the degree of similarity between the student's native language and the one he is trying to learn. Since no individual student matches another in all of these matters, the classroom language teacher is faced every day with the necessity of making astute decisions. The more "aptitude" the student has, the less time need be spent on making him aware of the devices of the language and the more quickly can he be guided into concentrating on ideas to be expressed through them. Yet that very ability is gained through the practice of the language itself as it is presented in steps of graduated difficulty. It is the teacher who must hold the class together when some of its members are more ready than others to move on to consideration of something more complicated. It is the teacher who must maintain the challenge for everyone while the slower as well as the more 
advanced get the practice they need in actually using the language if we are to be able to say eventually that they "know" it. In these matters of manipulating the class, no matter what size, focus can be the teacher's reliable tool. There is a great range for the speaker's attention to span-and often in the same utterance-between the minutest detail of grammar or pronunciation, in the one direction, to the minutest nuance in meaning couched in the expression of the most profound thought, in the other. The teacher must judge the individual student's ability to maintain control over the language's devices and choose out of this vast area where to focus his attention without leading him beyond his depth.

It is this balance of control over the language devices used and the ideas expressed which is the strength as well as the bugbear of the oral drill technique. The teacher must be on his toes. As in the traditional classroom situation it takes no great effort to find a subject of interest for a class to talk about. But what use is the talking if the pronunciation is incomprehensible and the word order, forms, and other grammatical matters are scrambled in such a way as to be incoherent? Interrupting the student's speech with corrections is not the answer. Everyone knows how unpleasant-not to say futile-this procedure is; and surely no one regrets that it is being supplanted as a teaching technique. Much better if the mistakes are prevented; and this can be done only if it is clear to everyone in the classroom just what is expected. Hence, the utterances must be controlled. That is, the word order and the forms to be used in that word order must be clearly indicated regardless of the subject matter.

Thanks to the element of control in the oral drill technique, it need not be limited to individual recitation but can be a very effective means of making it possible for all the members of the class to practice at the same time. Thus it provides for efficient use of time and personnel. Nor should the psychological value of unison drill be overlooked: Many students find it comforting and reassuring to know that their first ventures in new sounds are made in company with other neophytes. And for this reason experienced teachers use unison drill inevitably when introducing new patterns or when correcting particularly sensitive students.

Unison drill can also be used as a means of changing the pace of the classroom work and as a device for reinforcement during the learning process. Yet, contrary to what may seem to be true on first consideration, conducting unison drill requires great skill if maximum benefit is to be derived from it. 
Distinguishing individual perfermance through the chorus of voices must have first claim on the teacher's attention for his primary concern as always is to learn where more concentrated work is necessary either in encouraging individual students to more meticulous effort or in determining which exercise will next be appropriate for the trouble spotted.

Thus, when to ask the class to recite in unison and when to recite individually is another decision to be made by the teacher. The type of exercise, the mood as well as the ability of the class determine the choice. Perfection in the sense of "This is the way a native would say it" must be constantly held by the teacher and the student as the goal, and techniques for attaining this goal must be ever ready at the teacher's command depending on his diagnosis of the trouble spots.

These techniques may include anything as simple and obvious as varying pace to something as subtle as working through contrasting examples.

The value of contrast in setting up an exercise cannot be overestimated, and presumably it has been used in the preparation of the material the class is working with: that is, (1) the subject matter being drilled by the exercises has been determined as troublesome through contrastive analysis of the native and target languages; and (2) those contrasting devices used by speakers of the target language themselves are presented as such in the drills, in an effort to make their content seem natural from the point of view of a native speaker. However, the teacher in the classroom can also rely on contrast as an indispensable aid in the business of breaking old habits and establishing new. For instance, in the matter of hearing and producing the new sounds, the teacher might ask himself: "What native language sound is the student confusing this with?" Or "What sound in his own language is this the same as? He doesn't realize it is the same because he is accustomed to using it in the middle of the word and here he must learn to use it at the beginning." (The / $/$ / of French for English speakers, for instance.) Or "What has he already learned that this is similar to?"

Thus, thinking in terms of contrast can provide a teacher with a quick diagnosis of why the student is having trouble and a quick example far more effective in eradicating a mistake than a protracted lecture would be. ${ }^{5}$ But as in all matters, a word of caution:

The teacher must not lose sight of the goal: the ability to handle automatically the devices of the new language. This requires what we call "thinking in the new language." All efforts 
must be channeled in this direction and the use of anything to speed up the process of attaining it is justified. However, switching back and forth from native to target language can slow down progress. And here again the teacher has a decision to make: "Will reminding the student of his native language at this point hurt him more than it will help him?" Until results of controlled experiments are available, the answer to this is still to be subjectively arrived at. Obviously, it will depend on what we have included as student aptitude as well as the trouble spot involved and whether it can be handled through what the student already knows of the new language.

For consistency's sake in the daily guidance of the class as well as because of the cumulative nature of the learning process, however, contrast can and should be used without stint in referring back to what has already been learned. A judiciously chosen example to point up contrast in the alreadyacquired with the now-to-be-acquired is a much more effective approach than a long rigmarole of esoteric terminology.

Terminology is for the student who is learning about the language, not the one who is learning to use it. And this also is a precept that the teacher must keep in the front of his mind. The teacher knows the terminology but he must bridle the temptation to use it by first asking himself whether the knowledge will actually help the student in the primary concern of establishing habits. In most instances he is likely to decide that the quickest and therefore best results are to be obtained through working by analogy from examples of "natural" utterances. Through these "natural" utterances the student learns the sound and the rhythm of the words and conversely the sound and rhythm themselves teach the "natural" utterance. The opportunity that oral drills present for demonstrating this is their distinct advantage. The rhythm and sound of the words can carry the class through the practice and the teacher will want to take full advantage of them. If he stops for corrections and these things are lost, he must anticipate that the exercise will bog down. Therefore, if he decides on the basis of what the class should be able to do and what it is supposed to be trying to do, that the correction must be made, then he must see that the rhythm and sounds are again ringing in the ears before he can expect to continue with the drill. This is true whether the work is unison or individual.

A system of hand signals and nods of the head are most effective for preserving the uninterrupted flow of the sounds of the new language. In addition, the teacher finds that his gestures have a very desirable side effect of keeping the students' 
eyes on him. Obviously, with the students' eyes on the teacher and with everyone understanding just what is expected through the teacher's motions as to who is to recite or what they are to talk about, there is a minimum of wasted time. But more important, perhaps, is the fact that with the student's eyes on the teacher and the teacher's eyes on the student, a more natural setting for the new language is being established: one of communication between human beings.

It is for this reason that some teachers prefer to prompt the students' performance by means of large charts that can be seen by everyone so that the students' eyes need never stray from the front of the room. Others feel that the glance to a cue (picture or other) in the book doesn't necessarily mean that the attention is lost or that the basic concept of communicating is distorted. They rely on the necessity to watch the teacher's gestures, and to a great extent on the speed with which the drill is performed, to ensure that the attention is not lost.

Maintaining a reasonable speed through the drills is another area where the teacher's judgment must be exercised. First and foremost, his guide must be that it should not be allowed to distort the sounds. Yet within the range of speed a native speaker might use are various degrees of possibilities which the teacher can choose from.

Here again the matter of the student's aptitude must be taken into consideration. Under no circumstances, however, should the teacher allow the utterance to be broken up with a series of "...uh ...uh ...uh". This is greatly to be deplored, not only because this kind of stuttering is boring to listen to, but above all because it utterly destroys the "feeling" of the language. If repeating after the teacher does not suffice to eliminate the "uhs" and enable the student to carry on the drill with the pace of the native speaker, then the diagnosis should no doubt be that the drill is too advanced and must be broken down into its parts and put together again.

For instance, if a class is having trouble with something like:

$$
\begin{aligned}
& \text { "I could read the lesson this morning because I } \\
& \text { studied it last night" }
\end{aligned}
$$

the teacher can quickly concoct a substitution drill for the various parts of the sentence:

I studied it last night

practiced

wrote

studied 
I could read the lesson this morning sing the song

mail the letter

read the lesson

and then put it all together again:

I could read the lesson this morning because I studied it sing the song mail the letter practiced read the lesson

last night.

wrote studied

The teacher gauges just how much of this is needed before the class can be expected to continue the exercise from which the lesson digressed. Or if it is a question-and-answer type of drill which the class is finding difficult, the teacher can ask for practice of the questions separately and then for practice of the answers and finally for both-one alternating with the other (preferably with two pupils participating as in a conversation).

Thus the teacher brings the students smoothly to the point of being able to handle any of the complicated structures, filling in according to their needs any gap not anticipated by the prescribed material.

But the teacher cannot be satisfied with simply uttering the corrected form. He must patiently insist that the students themselves produce it. The reason is obvious: it is the student - not the teacher-who needs the practice!

Still another consideration in the matter of judging just how fast an exercise should be performed is the fact that the ultimate goal is a spontaneous response, in the sense that the response of a native speaker is spontaneous. Therefore, the students should be pressed to their greatest ability. Pressure, of course, creates tension but in measured doses can do only good. To that end, then, the teacher will want to alternate pressure with periods of relief. One source of this can be the ability of the student to predict when he is going to be expected to recite. A systematic way of taking each student in turn gives in some measure the desired sense of relaxation: just as, conversely, calling on a student out of order can also be used with desirable effect, especially if he is at the point in his language learning where attention can be diverted from the devices he is expected to handle.

In any case the teacher must be ever alert for the good student who may be losing interest (because of the stage in the formation of the habit he thinks he has reached) and help him 
realize that he still has work to do-a matter of pronunciation, perhaps, that needs refining-just as he will want the poor student who may be losing interest to feel that he still has a chance. This can be done as it is done when teaching other subjects: through tactfully ignoring or pointing up mistakes as intuition based on experience indicates. All this, of course, is done with a long view toward the teacher's standard of ultimate performance. Yet never is this standard to be compromised. Only the well done should be praised, although this does not rule out the encouragement of a "That's better" with appropriate intonation. It is indispensable in drill-type exercises that the students understand from the beginning that slipshod performance will not be tolerated. Just how this is put across depends, of course, on the personality of the teacher, but insisting on careful, accurate work from the start will save agony for everyone later on.

The teacher's approach obviously must be adjusted to the student's level of intellectual maturity. There are games that can be adapted to the drill technique. (Guess what John has in his hand: It is a pencil. It is a book. It is a letter, etc.) but a teacher of adults might prefer to avoid them. The older the student and the more mature he is, the more patience he has with a drill labeled "drill." His satisfaction is derived from the ability he acquires in being able to handle those language devices drilled, and the teacher's ingenuity comes into play at a later stage in designating the subject matter he is to handle in demonstrating that ability.

Although admitting the value of the drill technique for the amount of control it affords over the student's performance, one may protest that this type of exercise does not teach the language as it is naturally used. The answer is simply that more or less successful application can be made of the principle involved. The better the drill, the more nearly it reproduces a "natural" utterance in a "natural" setting. The clever teacher if he deems it necessary can, through a carefully chosen context for carefully chosen items of pronunciation, grammar, or vocabulary, create a natural setting for all types of drill exercises.

Persons who protest on this point usually have in mind that the spoken language is a matter of conversation-in the sense that questions and answers are conversation-ranging over a wide choice of subject matter. ${ }^{6}$ But if we think of the spoken language in its broader sense of a means of communicating ideas among human individuals, we need not be confined to a question-and-answer type of repartee, valuable as that may be for practicing various language problems. Nor, on the other 
hand, are successful drills limited to the substitution type. A discussion of the possible forms they might take is beyond the scope of this paper, but let me state simply that their purpose is to establish a speech habit through repetition, the drudgery of which can be camouflaged to a greater or lesser degree depending on the skill of the designer and the desirability of the camouflage.

Experience indicates that elaborate exercise settings are more or less necessary depending not only on the ability of the student to handle grammar and pronunciation, and his maturity, as stated, but also on the points of similarity in context existing between the native and target languages. To teach that "The man had pork for dinner" as simple substitution item for eggs or fish or cheese would require a much more complicated exercise setting if we were teaching English to a native speaker of Urdu than it would if we were teaching it to a native speaker of French.

Thus, since language drills should convey meaning undistorted, items to be used in them cannot be chosen indiscriminately. If, for instance, the names of these items are to be used in a drill: bread, butter, fruit, ink, chalk, potatoes, then "John eats ..." would not be chosen as the regularly recurring part of the utterance; for although grammatically correct, it would yield nonsense.

Caution, therefore! The drill technique is deceptive. It takes a skilled teacher to employ it to best advantage. It can be boring, but it need not be. And the reward for the teacher adept at its use is a highly motivated classroom of students actually speaking another language.

\section{FOOTNOTES}

${ }^{1} \mathrm{~J}$. Donald Bowen, "The Modern Language Association College Language Manual Project," PMLA, LXXIV (September 1959), 25.

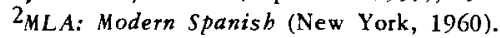

${ }^{3}$ Leonard Bloomfield, Outline Guide for the Practical Study of Foreign Languages (Baltimore, 1942) p. 12.

${ }^{4}$ Bowen, p. 25.

5 See Charles C. Fries, "Preparation of Teaching Materials, Practical Grammars, and Dictionaries, Especially for Foreign Languages," Eighth International Congress of Linguists, 738-746; reprinted in Language Learning. IX, 1 and 2 (1959), 43-50.

Fries, Teaching and Learning English as a Foreign Language (Ann Arbor, 1953). Robert Lado, Linguistics Across Cultures (Ann Arbor, 1957).

Gerald Dykstra, "Perspective on the Teacher's Use of Contrast," Language Learning, VI, 3 and 4 (1956), 1.

OSee, for instance, FL. Program Note "Drilling is not conversation," PMLA, LXXV, 4, Part 2, Sept. 1960, p..viii. 